\title{
Strategies for living with the risk of anaphylaxis in adolescence: qualitative study of young people and their parents
}

\author{
Michael Gallagher ${ }^{1},{ }^{*}$ Allison Worth², Sarah Cunningham-Burley², Aziz Sheikh² \\ ${ }^{1}$ School of Geographical and Earth Sciences, University of Glasgow, Glasgow, UK \\ ${ }^{2}$ Allergy and Respiratory Research Group, Centre for Population Health Sciences, The University of Edinburgh, Edinburgh, UK
}

Received 16th April 2012; revised 15th June 2012; accepted 25th June 2012; online 8th August 2012

\begin{abstract}
Background: Adolescents with anaphylaxis are at increased risk of fatal outcomes. Gaps in their knowledge of day-to-day and emergency management have been identified. There are also gaps in services available to support adolescents at risk of anaphylaxis.

Aims: To explore the experiences and healthcare needs of adolescents living with the risk of anaphylaxis; to understand the perspectives of their parents; and to look at how care might be improved.

Methods: A qualitative study was undertaken using in-depth interviews with adolescents with a recent history of severe allergic reactions and with their parents.

Results: Twenty-six adolescents at risk of anaphylaxis living in Scotland and their parents $(n=28)$ were recruited. Most anaphylactic reactions reported by participants appeared to result from accidents, misinformation, or inexperience. For many, management involved finding a balance between taking their allergies seriously whilst not allowing these concerns to dominate their lives. Risks were often difficult to judge, with reactions sometimes taking place even after careful checking of meal ingredients. Most admitted taking some risks with trace-labelled foods. Appropriate healthcare support for adolescents in learning to manage the risk of anaphylaxis independently and advice and support for their parents was inconsistently provided.

Conclusions: Adolescents tend to see their risk management strategies as 'good enough', but these strategies were often inconsistent with clinical best practice and, in some cases, had not prevented reactions. Building on adolescents' existing skills and knowledge and the use of Internet and associated social media resources may help to support more effective self-management among adolescents.

(C) 2012 Primary Care Respiratory Society UK. All rights reserved.

M Gallagher et al. Prim Care Respir J 2012; 21(4): 392-397

http://dx.doi.org/10.4104/pcrj.2012.00072
\end{abstract}

Keywords adolescents, allergy, anaphylaxis, management, qualitative

See linked editorial by Lockey on pg 365

The full version of this paper, with online appendix,

is available online at www.thepcrj.org

\section{Introduction}

Previous research has shown that adolescents have particularly high rates of severe and fatal anaphylactic reactions. ${ }^{1-3}$ The transition from childhood dependence to adult independence and the broadening of social horizons may present particular risks for adolescents with food allergy, which is the dominant trigger in young people experiencing anaphylaxis., ${ }^{4,5}$ The transfer of responsibility for managing the risk of anaphylaxis (such as avoiding triggers) from parents to adolescents coincides with more exposure to risk and, potentially, less careful risk management. ${ }^{6,7}$ Individual tolerance of risk varies, ${ }^{8}$ and risk-taking/learning through one's mistakes can be seen as a necessary developmental process in adolescence. ${ }^{9}$ Teenagers with food allergy must learn to balance threats to their personal safety with threats to their social identity. ${ }^{10}$

The negative psychosocial impact of food allergy on young people and their families is well-known, ${ }^{11,12}$ and balancing safety and quality of life in food-allergic adolescents presents considerable

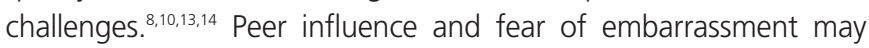

\footnotetext{
* Corresponding author: Dr Allison Worth, Allergy and Respiratory Research Group, Centre for Population Health Sciences, The University of Edinburgh, Medical School, Teviot Place, Edinburgh EH8 9AG, UK.

Tel: +44 (0)131 6509463 Fax: +44 (0)1316509119 E-mail: Allison.Worth@ed.ac.uk
} 
lead to increased risk-taking behaviour, both in relation to exposure to known triggers and failure to carry epinephrine (adrenaline). ${ }^{6,13-15}$ High levels of anxiety in children and parents do not appear to be associated with improved adherence to key management strategies such as allergen avoidance and carrying medication. ${ }^{16}$

The psychosocial factors which contribute to increased incidence of anaphylactic reactions in this group remain poorly understood. A better understanding of the beliefs, expectations, and behaviours underlying adolescent risk management are prerequisites to improving support for this group..$^{17,18}$

This study aimed to address this gap by providing detailed insights into how adolescents and their parents live with and manage the risk of anaphylaxis, and to explore their views on how to improve anaphylaxis management. Findings relating to adolescents' use of epinephrine auto-injectors have been published previously. ${ }^{14}$ This paper focuses on adolescent and parental perceptions of risk and risk management.

\section{Methods}

A qualitative study using semi-structured interviews was undertaken to produce detailed data about adolescents' attitudes, behaviours, and experiences. We sought adolescents at high risk of anaphylaxis, indicated by: (1) anaphylaxis in the last 5 years; or (2) an earlier reaction and/or testing indicating high risk. We used the UK Resuscitation Council's definition of anaphylaxis as 'a hypersensitivity reaction involving airway problems and/or circulatory problems'. ${ }^{19}$ Those who had previously experienced only mild reactions or reactions in early childhood were thus excluded.

\section{Recruitment}

Participants were purposively recruited through school nurses, specialist clinicians and primary care via the Anaphylaxis Campaign (the main UK patient support organisation) website and via a press release. We sought to recruit participants from all ages within the teenage years of both sexes living in different parts of Scotland (to explore different healthcare configurations and urban/rural situations). Interviews continued until we reached data saturation (i.e. when no significant new information was gathered from interviews).

\section{Data generation}

In-depth semi-structured interviews, each approximately 1 hour long, were carried out with adolescents and their parents using topic guides (see Appendix 1 available online at www.thepcrj.org). These were developed from reviewing the literature, from discussions with adolescents at risk of anaphylaxis, parents and health professionals and from a previous study. ${ }^{6}$ At the start of each interview, participants were given an information sheet and an opportunity was given for questions prior to completion of the consent forms.

Face-to-face interviews were conducted by one of the authors (MG) at the participant's place of choice, usually their home. Most chose to be interviewed alone, but in some cases parents, siblings and/or partners were also present (32\% of adolescent interviews; $38 \%$ of parent interviews). Interviews were digitally audio-recorded. We use pseudonyms for participants in the presentation of data to preserve anonymity.

\section{Data analysis}

All recordings were transcribed verbatim, anonymised, entered into NVivo software and thematically coded. The coding framework was informed both deductively by the research aims and recent literature on anaphylaxis and adolescent health ${ }^{23,5,12,17,20,21}$ and inductively by the content of the data based on detailed reading of transcripts by two of the authors (MG and AW) and discussion with the other investigators.

Analytical validity was ensured through comparison of transcripts coded independently by MG and AW during the development of the coding framework. Coding only began when MG and AW achieved a high level of agreement between their interpretations. Careful searching for data disconfirming emerging findings was carried out, aiding refinement of the analysis. ${ }^{22}$

\section{Ethics}

Ethical approval was obtained from Fife \& Forth Valley Research Ethics Committee and management approval from the relevant NHS organisations.

\section{Results}

We recruited 26 adolescents aged 13-19 years and their parents $(n=28)$; most lived in central Scotland. In five cases, both parents were interviewed; three parents did not wish to be interviewed. The majority of adolescents (88\%) had food-related allergies, predominantly to peanuts and/or tree nuts. Participant characteristics

\section{Box 1: Novel findings}

1. Although some adolescents described embarrassment at being perceived as different from their peers and some took risks with food when eating out, adolescents' accounts of reactions suggested that the majority of these did not result from stereotypically irresponsible behaviour (such as alcohol misuse or deliberate exposure to known allergens). Most took place in everyday situations and appeared to result from accidents, misinformation, or inexperience.

2. Most adolescents took an active role of some kind in managing their allergies, although some were more conscientious than others. Parents worked hard to ensure adolescents took responsibility for risk management as they became older.

3. Several adolescents and parents emphasised the importance of maintaining a balance between taking the risk of anaphylaxis seriously and not allowing it to dominate their lives.

4. When eating away from home, many adolescents and their parents found risks difficult to judge. Several reported reactions even after careful checking of ingredients.

5. Adolescents' assessments of risk often conflicted with the advice given by clinicians and patient support groups. Most adolescents ate trace-labelled foods and several ate Asian food, not realising the dangers.

6. Adolescents and parents reported variable levels of support from health services. Some had regular reviews with specialists while others received no support other than repeat prescriptions for epinephrine auto-injectors.

7. Primary care staff had very limited involvement in supporting anaphylaxis management.

8. Most adolescents did not think that written anaphylaxis management plans, as advocated by specialists, would be helpful to them in managing their condition. 
Table 1. Characteristics of participants

\begin{tabular}{|c|c|c|c|c|c|}
\hline No. & Age & Sex & Anaphylaxis triggered by & Referral source & Parent interviewed \\
\hline 1 & 19 & $\mathrm{M}$ & Peanuts, fish, shellfish & Specialist & Mother \\
\hline 2 & 16 & $\mathrm{M}$ & Peanuts, tree nuts & School nurse & Mother \\
\hline 4 & 13 & $\mathrm{~F}$ & Unclear: possibly idiopathic & School nurse & None \\
\hline 5 & 14 & $\mathrm{M}$ & Peanuts & School nurse & Father \\
\hline 8 & 16 & $\mathrm{M}$ & Peanuts, tree nuts & Anaphylaxis Campaign & Mother \\
\hline 9 & 19 & $\mathrm{~F}$ & Peanuts, tree nuts, insect stings & Anaphylaxis Campaign & Mother and father \\
\hline 10 & 13 & $\mathrm{~F}$ & Peanuts & Anaphylaxis Campaign & Mother \\
\hline 11 & 14 & $\mathrm{M}$ & Peanuts, tree nuts? & Anaphylaxis Campaign & Mother and father \\
\hline 16 & 17 & $\mathrm{~F}$ & Peanuts & Press release & None \\
\hline 17 & 16 & $\mathrm{M}$ & Peanuts, tree nuts & Press release & Mother and father \\
\hline 18 & 19 & $\mathrm{~F}$ & Horses & Press release & None \\
\hline 19 & 19 & $\mathrm{M}$ & Peanuts, tree nuts & Press release & Mother \\
\hline 20 & 15 & $\mathrm{~F}$ & Milk, eggs, nuts, sesame & Press release & Mother \\
\hline 21 & 16 & $\mathrm{~F}$ & Idiopathic & Specialist & Mother \\
\hline 22 & 16 & $\mathrm{~F}$ & Tomatoes and other fleshy fruits & Specialist & Mother \\
\hline 23 & 14 & $\mathrm{~F}$ & Peanuts & Specialist & Mother \\
\hline 24 & 13 & $\mathrm{M}$ & Milk, peanuts, egg & Public health nurse & Mother \\
\hline
\end{tabular}

are shown in Table 1.

We focus here on findings which go beyond the existing literature, summarised in Box 1 and reported in detail below.

\section{Experiences of anaphylaxis}

Our data do not support the notion that high rates of severe reactions experienced by adolescents result from casual inattention, reckless behaviour, or a lack of awareness of their mortality. On the contrary, some participants said that the experience of anaphylaxis had left them with a heightened sense of danger. Although parents worried about the influence of alcohol use on teenagers' behaviour, no reactions appeared to have resulted from this. In general, reactions took place in everyday situations: in the home, at school, in restaurants and other catering outlets, at weddings and parties.

In several cases, reactions had taken place despite careful attempts to avoid allergens, sometimes with parental approval of the trigger:

"... she [a shop assistant] checked the labels and she said 'no you'll be fine there are no nuts in it at all', and of course it just, it touched his tongue and it was boof! ... Antony had obviously taken it, with her insisting that it was fine, because he, obviously there was an element of trust there. And I said it would be OK and I was wrong." (Mother of Antony, 14)
Managing allergies and preventing further reactions

Most participants reported taking an active role in managing their allergies, although some were more conscientious than others. All the adolescents reported attempts to avoid allergens by checking ingredients. Most reported carrying epinephrine auto-injectors at least some of the time, although some - particularly males admitted that they often did not carry them. Only one young man said that he never carried an auto-injector.

Several interviewees said that their allergies had a major impact on their lives, reporting a sense that they always had to be alert to the danger of a reaction:

"It's really a pain because I have to think about it all the time

. it's always got to be at the back of my mind that has it got nuts in it and things, you can't eat whatever anyone else can eat and things, it's quite annoying." (Donald, 19)

Overall, the data suggested that most adolescents tried to find a balanced attitude to management, taking their allergy seriously whilst not allowing it to dominate their lives:

"I need to kind of live my life on the risk that something is going to happen or something might never happen." (Claire, 16) 
Parents perceived the increased risks of adolescence as teenagers having more freedom, more choice, being subject to greater peer pressure, and potentially adopting more risky behaviours such as drinking alcohol which might make them less careful. Most parents recognised the need for their children to become independent, despite the risks this might involve:

"I would say this time now up until early adulthood is the most vulnerable time ... This will be the time coming up where he's got more choices and it's a time where you want him to be confident in everything that he does and you don't want him to be frightened." (Mother of Callum, 13)

Previous research suggests that management plans may be effective in supporting those living with severe allergies. ${ }^{23,24}$ However, the majority of adolescents in our study did not think that such plans would be helpful for long-term management. While some saw value in simple emergency plans, many thought that plans covering dayto-day management would be excessive and might add unnecessary hassle to their lives. Some expressed the view that management knowledge was best learnt verbally or experientially rather than written down:

"Talking to a specialist, I think that would be much better than a written plan because you're talking to somebody face to face and they're directly telling you." (Karen, 13)

\section{Eating away from home}

Participants found eating away from home to be one of the most significant challenges for day-to-day management. Risks were often difficult to judge, with reactions sometimes taking place even after careful checking. All adolescents and parents discussed the challenges of managing a food allergy in the context of a normal teenage social life. Some described restricting their lives in terms of eating out and foreign travel because of the difficulty of risk management, but most grappled with balancing risk and active social engagement on a regular basis. Asian foods appeared to be important in adolescents' social lives, but adolescents found the risks associated with such foods to be particularly difficult to judge. Some were optimistic in their assessments of the risks associated with eating Asian food and carrying their epinephrine auto-injector was perceived as ameliorating risk-taking:

"She does have curries and she'll have her EpiPen and her antihistamines with her, because she eats Korma ... she's prepared to take the minimal risk of having a curry because she thinks she's got everything in her bag and it's fine and it's safe, well that's OK by her." (Mother of Catriona, 19)

These perceptions - that the risk is low from eating curries and the epinephrine auto-injector provides protection - contrast sharply with the viewpoint of allergy specialists who tend to advocate avoidance of such foods.

\section{Risk and 'may contain' labels}

Most participants admitted taking some risks with trace-labelled foods (i.e. those that state a food 'may contain' nuts or 'cannot guarantee nut-free'). Many adolescents expressed the belief that manufacturers used the labels merely to avoid litigation and that, given the prevalence of these labels, total avoidance was unrealistic:

"Avoiding products with nuts isn't so hard, it's avoiding things that are 'may contain' that's the real trouble. Because if you do cut everything that's 'may contain' from your diet it restricts it severely, so at times you do have to try and make an informed decision on something." (Rebecca, 17)

No participants reported anaphylaxis following ingestion of a tracelabelled food, although one peanut allergic young man reported a mild reaction from chocolate sweets labelled as 'may contain traces of nuts'. He had subsequently avoided this product but continued to eat other foods with trace labelling. Again, these behaviours conflict with the perspectives of allergy professionals who generally advise that trace-labelled food should never be eaten because crosscontamination is unpredictable.

\section{Support from healthcare professionals}

The reported level of care received from health services varied amongst participants, partly due to a lack of specialist adolescent/adult allergy services in all but one area of Scotland. Some adolescents had received no specialist input at all, despite in some cases having been treated for anaphylaxis in accident and emergency departments on multiple occasions. Others had regular reviews with specialists which they tended to view positively. In general, those with regular specialist contact appeared to be better informed about managing their allergies than those with no ongoing specialist support:

"She's really nice, she like, every time I go up if I have a problem wi' something then she'll go through it, she'll explain it and stuff like that and she really does help." (Claire,

16)

Some adolescents reported having had specialist care from paediatric services but no follow-up after that.

Many participants reported that primary care services had limited involvement in anaphylaxis risk management. Whilst a few participants recounted good experiences and a few recounted memorably bad experiences with GPs, the majority appeared to have little or no input:

"I mean they just hand out, they just keep reissuing the

EpiPen, you'd have thought they might just want to see

him." (Mother of James, 17)

\section{Transition from parental to self-management}

The transition to independence is a core feature of adolescence and presents particular challenges for teenagers with severe allergies and their parents. In general, mothers were more closely involved with managing this transition than fathers. Support for parents in managing the transition came largely from the Anaphylaxis Campaign:

"In terms of education of the problems and living with it, then undoubtedly the Anaphylaxis Campaign has been the one there." (Father of Tom, 14)

The most common responsibilities handed over to adolescents were those of carrying medication and checking food ingredients. Most older adolescents and their parents said that they had completed this transition and looked back on it as a gradual process, part of growing up and becoming more independent. Some younger participants reported embarrassment at having to ask about food ingredients in public. In some cases friction was apparent on the 
issue of carrying medication, particularly between boys and their mothers.

\section{Discussion}

\section{Main findings}

Contrary to common stereotypes, most adolescents at risk of anaphylaxis took some kind of active role in managing their allergies. What this involved, however, varied greatly. Some were highly conscientious (e.g. carrying epinephrine at all times, avoiding all trace-labelled products) while others had less stringent management styles. Many displayed extensive knowledge of anaphylaxis management, although some had significant gaps, particularly with regard to knowing when and how to use epinephrine. ${ }^{14}$ The experiences of adolescents of various ages indicate how the transition from parental to adolescent responsibility for anaphylaxis management develops gradually over time.

Written management plans, strongly advocated by professionals, ${ }^{23-26}$ were not perceived by adolescents as helpful. It may be that these are of greater value to professionals as a means of structuring discussion of allergy management and of recording and monitoring what has been agreed than they are to adolescents who generally did not see that written information would enhance selfmanagement.

\section{Strengths and limitations of this study}

The use of in-depth semi-structured interviews produced rich nuanced accounts of how adolescents manage severe allergies. The most obvious limitation of this study - as with most qualitative work - is the relatively small number of participants and the potential restrictions this places on the generalisability of the results. However, data saturation was reached and the insights gained from our indepth intensive approach provide credible and potentially transferable understandings of adolescents' diverse behaviours and attitudes. The combined use of interviewing, scenarios for participants to comment on, and the ranking exercise using visual tools (see Appendix 1 available online at www.thepcrj.org) proved to be an excellent way to open up discussion.

Where joint interviews were conducted with adolescents and parents, there is a possibility that either party might have been inhibited in fully expressing their views or, in the adolescents' case, discussing risk-taking behavior. Our experience of the interviews suggests that, conversely, parents encouraged adolescents to speak comprehensively and the interaction within the joint interviews highlighted pertinent aspects of the relationship between them.

\section{Interpretation of findings in relation to previously} published work

Several of our findings confirm previous research. Eating away from home was found by participants to be challenging, ${ }^{27}$ with Asian cuisines reported as particularly risky. ${ }^{28}$ Trace labels (such as 'may contain nuts') were widely found to be frustrating and confusing. ${ }^{6,29,30}$ Underuse of epinephrine auto-injectors and limited knowledge of auto-injector administration technique were evident in participants' accounts. . $^{1420,31}$

In contrast to some of the wider literature on adolescents with long-term conditions, ${ }^{21}$ anaphylaxis in at-risk adolescents seemed unlikely to result from stereotypical risky 'teenage' behaviours such as alcohol use, despite parental worries about this. Assessing risks was challenging, primarily due to the complexity of food labels, the opacity of food manufacturing and preparation, and the widespread lack of public awareness of food allergy. Some had responded to these challenges with an attitude of extreme caution which restricted aspects of everyday life, while others opted to take risks for the sake of a 'normal' life. Some adolescents reported taking risks that clinicians might find alarming, particularly with Asian food. Misunderstanding about the meaning of 'may contain' labels and a belief that having an auto-injector available guarantees safety may lead to unnecessary risk-taking and has been found to contribute to deaths from anaphylaxis. ${ }^{3}$

\section{Implications for future research, policy and practice} The views and experiences of adolescents are instructive for clinical practice. We suggest that clinicians may be more effective by working to enhance and extend existing management behaviours of adolescents rather than giving advice based on an impersonal 'gold standard' of management. A pragmatic approach might involve focusing on high-risk scenarios, such as Asian foods, ${ }^{28}$ and discussing the meaning of 'may contain' labels. Stereotypes of teenagers as reckless appear inaccurate and over-generalised; they are therefore likely to be unhelpful for clinicians wishing to engage in meaningful discussions about management with adolescent patients. Written management plans may be useful for facilitating such discussions, but our data suggest that there is little value in giving copies to adolescents without appropriate discussion and negotiation.

Given that adolescence is known to be associated with an increased risk of severe and fatal reactions, the lack of continuity between paediatric and adult services is a significant gap in provision. Transition clinics have been helpful for young people with other health conditions to promote successful transition to adult healthcare. Transition planning with teenagers and parents, incorporating the knowledge deficits and practical problems identified by adolescents and parents in this study, is recommended as a core part of clinical practice in both primary and specialist care. ${ }^{32,33}$ Clinical advice for parents should include encouraging them to support adolescents to gradually 'take over' responsibilities such as speaking to waiters, carrying epinephrine, and checking that autoinjectors are in date.

The limited involvement of primary care in supporting patients with severe allergy is also concerning. The possibility of practice nurses providing such support, as they do for other long-term conditions such as asthma, should be explored. ${ }^{34}$

Further research might usefully explore the use of text messaging, audio-visual, internet and social networking sites, which are central means of communication for adolescents, as a means of providing information and support for managing the risk of anaphylaxis. For example, a Canadian site (www.whyriskit.ca) run by young people with food allergy includes podcasts, videos and an e-magazine specifically aimed at improving knowledge, skills, and management among young people.

\section{Conclusions}

This study suggests that the high risk of severe and fatal anaphylaxis 
in adolescents is not necessarily a consequence of teenage irresponsibility. Eating away from home was a particular challenge and some adolescents found this to be a major lifestyle restriction. The lack of healthcare support for many adolescents at risk of anaphylaxis and their parents was notable. Transition planning may help to support the development of self-management skills.

\section{Handling editor Dianne Goeman}

Acknowledgements We would like to thank the adolescents and parents who participated in the study and those who helped with recruitment.

Conflicts of interest AS has received support from ALK-Abello, Napp, Phadia and Pfizer to attend educational meetings and conferences in the previous 3 years. AW has received support from ALK-Abello and Napp to attend conferences in the previous 3 years. AS is the Joint Editor-in-Chief of the PCRJ but was not involved in the editorial review of, nor the decision to publish, this article. MG and SC-B declare that they have no conflicts of interest in relation to this article.

Contributorship All authors made substantial contributions to the conception and design of or acquisition of data or analysis and interpretation of data; drafted the article and revised it critically for important intellectual content; and gave final approval of the version to be published.

Funding The study was funded by the Chief Scientist Office of the Scottish Government's Health Department. The research team is independent of the funders and the views expressed are those of the researchers, not the funding body.

\section{References}

1. Sampson MA, Munoz-Furlong A, Sicherer SH. Risk-taking and coping strategies of adolescents and young adults with food allergy. J Allergy Clin Immunol 2006;117:1440-5. http://dx.doi.org/10.1016/j.jaci.2006.03.009

2. Bock SA, Munoz-Furlong A, Sampson HA. Further fatalities caused by anaphylactic reactions to food, 2001-2006. J Allergy Clin Immunol 2007;119:1016-18. http://dx.doi.org/10.1016/j.jaci.2006.12.622

3. Pumphrey $\mathrm{R}$, Gowland $\mathrm{H}$. Further fatal allergic reactions to food in the United Kingdom, 1999-2006. J Allergy Clin Immunol 2007;119:1018-19. http://dx.doi.org/10.1016/j.jaci.2007.01.021

4. Alves B, Sheikh A. Age-specific aetiology of anaphylaxis: a study of routine hospital admission data in England. Arch Dis Child 2001;85:349. http://dx.doi.org/10.1136/adc.85.4.348b

5. Lyons AC, Forde EME. Food allergy in young adults: perceptions and psychological effects. J Health Psychol 2004;9:497-504. http://dx.doi.org/10.1177/1359105304044032

6. Akeson N, Worth A, Sheikh A. The psychosocial impact of anaphylaxis on young people and their parents. Clin Exp Allergy 2007;37:1213-20. http://dx.doi.org/10.1111/j.1365-2222.2007.02758.x

7. Greenhawt MJ, Singer AM, Baptist AP. Food allergy and food allergy attitudes among college students. J Allergy Clin Immunol 2009;124:323-7. http://dx.doi.org/10.1016/j.jaci.2009.05.028

8. Mackenzie H, Roberts $G$, van Laar D, Dean T. Teenagers' experiences of living with food hypersensitivity: a qualitative study. Pediatr Allergy Immunol 2010;21:595602. http://dx.doi.org/10.1111/j.1399-3038.2009.00938.x

9. Christensen P, Mikkelsen MR. Jumping off and being careful: children's strategies of risk management in everyday life. Sociol Health IIIness 2008;30:112-30. http://dx.doi.org/10.1111/j.1467-9566.2007.01046.x

10. DunnGalvin A, Gaffney A, O'Hourihane JO'B. Developmental pathways in food allergy: a new theoretical framework. Allergy 2009;64:560-8. http://dx.doi.org/10.1111/j.1398-9995.2008.01862.x

11. Cummings AJ, Knibb RC, King RM, Lucas JS. The psychosocial impact of food allergy and food hypersensitivity in children, adolescents and their families: a review. Allergy 2010;65:933-45. http://dx.doi.org/10.1111/j.1398-9995.2010.02342.x

12. Mandell $D$, Curtis R, Gold M, Hardie $S$. Families coping with a diagnosis of anaphylaxis in a child. $A C l$ International 2002;14:96-101

http://dx.doi.org/10.1027/0838-1925.14.3.96

13. Monks $\mathrm{H}$, Gowland MH, MacKenzie $\mathrm{H}$, et al. How do teenagers manage their food allergies? Clin Exp Allergy 2010;40:1533-40.

http://dx.doi.org/10.1111/j.1365-2222.2010.03586.x
14. Gallagher M, Worth A, Cunningham-Burley SC, Sheikh A. Epinephrine auto-injector use in adolescents at risk of anaphylaxis: a qualitative study in Scotland, UK. Clin Exp Allergy 2011;41:869-77. http://dx.doi.org/10.1111/j.1365-2222.2011.03743.x

15. Marklund B, Wilde-Larsson B, Ahlstedt S, Nordström G. Adolescents' experiences of being food-hypersensitive: a qualitative study. BMC Nursing 2007;6:8. http://dx.doi.org/10.1186/1472-6955-6-8

16. Cummings AJ, Knibb RC, Erlewyn-Lajeunesse M, King RM, Roberts G, Lucas IS. Management of nut allergy influences quality of life and anxiety in children and their mothers. Pediatr Allergy Immunol 2010;21:586-94. http://dx.doi.org/10.1111/j.1399-3038.2009.00975.x

17. Rodham K, Brewer H, Mistral W, Stallard P. Adolescents' perception of risk and challenge: a qualitative study. J Adolescence 2006;29:261-72. http://dx.doi.org/10.1016/j.adolescence.2005.05.012

18. Horne R. Compliance, adherence and concordance: implications for asthma treatment. Chest 2006;130:65-72. http://dx.doi.org/10.1378/chest.130.1_suppl.65S

19. Soar J, Pumphrey R, Cant A, et al. Emergency treatment of anaphylactic reactionsguidelines for healthcare providers. Resuscitation 2008;77:157-69. http://dx.doi.org/10.1016/j.resuscitation.2008.02.001

20. Simons FER, Clark S, Camargo CA. Anaphylaxis in the community: learning from the survivors. J Allergy Clin Immunol 2009;124:301-06.

http://dx.doi.org/10.1016/j.jaci.2009.03.050

21. Sawyer SM, Drew S, Yeo MS, Britto MT. Adolescents with a chronic condition: challenges living, challenges treating. Lancet 2007;369:1481-9. http://dx.doi.org/10.1016/S0140-6736(07)60370-5

22. Pope C, Ziebland S, Mays N. Qualitative research in health care: analysing qualitative data. BMJ 2000;320:114-16. http://dx.doi.org/10.1136/bmj.320.7227.114

23. Ewan PW, Clark AT. Efficacy of a management plan based on severity assessment in longitudinal and case-controlled studies of 747 children with nut allergy: proposal for good practice. Clin Exp Allergy 2005;35:751-6.

http://dx.doi.org/10.1111/j.1365-2222.2005.02266.x

24. Worth A, Nurmatov U, Sheikh A. Key components of anaphylaxis management plans: consensus findings from a national electronic Delphi study. J $R$ Soc Med Sh Rep 2010;1:42. http://dx.doi.org/10.1258/shorts.2010.010060

25. Hourihane $J O^{\prime} B$, Beirne P. Evidence of effectiveness of anaphylaxis management plans: are we waiting for Godot? Clin Exp Allergy 2007;37:967-9. http://dx.doi.org/10.1111/.1365-2222.2007.02754.x

26. Royal College of Paediatrics and Child Health (RCPCH). Care pathway for anaphylaxis. London: RCPCH, 2011. Available at: www.rcpch.ac.uk/ allergy/anaphylaxis (accessed 24 Aug 2011)

27. Pumphrey RSH. Lessons for management of anaphylaxis from a study of fatal reactions. Clin Exp Allergy 2000;30:1144-50. http://dx.doi.org/10.1046/j.1365-2222.2000.00864.x

28. Leitch IS, Walker MJ, Davey R. Food allergy: gambling your life on a take-away meal. Int J Env Health Res 2005;15:79-87. http://dx.doi.org/10.1080/09603120500062052

29. Food Standards Agency. 'May contain' labelling: the consumer's perspective. London: Food Standards Agency, 2002. Available at: www.food.gov.uk/ multimedia/pdfs/maycontainreport.pdf (accessed 12 Apr 2012)

30. Primeau M-N, Kagan R, Joseph L, et al. The psychological burden of peanut allergy as perceived by adults with peanut allergy and the parents of peanut-allergic children. Clin Exp Allergy 2000;30:1135-43. http://dx.doi.org/10.1046/.1365-2222.2000.00889.x

31. Sicherer SH, Forman JA, Noone SA. Use assessment of self-administered epinephrine among food-allergic children and pediatricians. Pediatrics 2000;105:359-62. http://dx.doi.org/10.1542/peds.105.2.359

32. Kennedy A, Sloman F, Douglass JA, Sawyer SM. Young people with chronic illness: the approach to transition. Intern Med J 2007;37:555-60. http://dx.doi.org/10.1111/j.1445-5994.2007.01440.x

33. Lugasi T, Achille M, Stevenson M. Patients' perspective on factors that facilitate transition from child-centered to adult-centered health care: a theory integrated metasummary of quantitative and qualitative studies. J Adolesc Health 2011;48:429-40. http://dx.doi.org/10.1016/j.jadohealth.2010.10.016

34. Upton J, Madoc-Sutton H, Sheikh A, Frank TL, Walker S, Fletcher M. National survey on the roles and training of primary care respiratory nurses in the UK in 2006: are we making progress? Prim Care Respir J 2007;16:284-90. http://dx.doi.org/10.3132/pcrj.2007.00068 


\section{Appendix 1: Interview guides}

\section{Adolescents}

Start by negotiating informed consent.

You don't have to answer any questions you don't want to. It's up to you how much you tell me. (00:10)

What are you allergic to?

What one word do you think best describes your allergy?

Write on flipchart paper and brainstorm

$\infty$ Why this word?

$\infty$ How severe is their anaphylaxis? How recent their last episode?

$\infty$ Tell me about your last episode.

(Should lead into discussion of experiences of and attitudes towards anaphylaxis, impact on their lives, role of parents, experience of support and information services (e.g. use of internet), experiences at school and with peer group)

$\infty$ Research shows that teenagers with allergy are more at risk of bad reactions than other age groups with allergies. Why do you think this is?

(Should lead to discussion of risk-taking, lifestyle, intended and actual behaviours, perceptions of risk, negotiation of responsibility with parents, context of adolescence, experiences of support services) (00:15)

How does your allergy affect your relationships with:
$\infty$ Parents
$\infty$ Brothers and sisters
$\infty$ Friends

(Scene should now be set for a discussion of management of the condition) (00:20) What do you do to keep your allergy under control?

$\infty$ Do you see your doctor about it?

$\infty$ Do you see a specialist? How often? 
Appendix 1.

$\infty$ Do you have an Epipen/Anapen? Do you carry it?

$\infty$ Are you comfortable carrying and using your Epipen/Anapen?

$\infty$ Do you avoid certain foods, certain situations?

$\infty$ Have you educated your friends about your condition?

$\infty$ Are there things you do at school?

$\infty$ Do these things work well - why/why not?

What help do other people give you? Parents, friends, teachers, doctors.

***|f not working, use scenarios at the end ${ }^{* * *}$

(00:25)

What - if anything - do you think would help teenagers to deal with their allergies better?

Ranking exercise, using range of options for interventions typed on laminated cards.

Put them in three piles: 'brilliant', 'OK' and 'rubbish'. Interviewer will also carry blank cards for their ideas.

1. More awareness - in schools, doctors, restaurants, etc.

2. Better food labeling [use food labels as props].

3. Get re-tested to see if I still have my allergy.

4. Refresher training for what to do in an emergency.

5. Watch a video of someone having a reaction and using Epipen.

6. Meet other teenagers who have allergies.

7. Text message reminders when Epipen goes out of date.

8. Make Epipen easier to carry.

9. A bracelet with information about my allergy.

10. A written plan for what to do in an emergency.

11. A written plan for dealing with my allergies day-to-day.

12. Talk to a specialist about my allergy and how to deal with it.

13. Educate my friends about allergies.

14. Find a treatment. 
Probing is *essential*, e.g.

$\infty$ 'more awareness' - for who? What should they be aware of?

$\infty$ 'a written plan' - have you ever had one? Who should write this? What would it contain? Show some examples.

$\infty$ 'treatment' - what should this be? Pills, injections, etc.

Ask: Which is the best idea of them all?

Use objects as prompts:

$\infty$ Epipen and Anapen trainers

$\infty$ Carry case

$\infty$ Translation cards

$\infty$ Food labels

$\infty$ Website printouts

$\infty$ AMPs

$(00: 40)$

If time, and if teenager is still up for talking at this point, or as an alternative if the ranking falls flat ...

Scenarios:

$\infty$ It's a friend's birthday and your mates are going out to a restaurant. You suspect that the food there might cause some problems for you.

$\infty$ You're going out for the night and don't have a bag to put the Epipen in.

$\infty$ People at your school are asking questions about your allergy and what you can and can't eat, and why.

$\infty$ Someone offers you a snack that is labelled 'may contain traces of nuts'.

$\infty$ You leave the house for the evening and then a few minutes later remember that you've forgotten to bring your Epipen with you.

$\infty$ You are about to kiss someone for the first time. You remember hearing something about how food traces in people's mouths can cause allergic reactions.

$\infty$ You want to go on holiday abroad with some mates but your parents are worried that something bad will happen. They say that you must decide, but they don't think it's a good idea.

(00:55)

Offer to replay audio recording. 
Appendix 1.

Explain what will happen next:

$\infty$ we will listen back to the recording

$\infty$ we will write down what you said

$\infty$ and then write this into a report with what other young people said

$\infty$ we'll send you a summary of the findings

Thank you. 


\section{Parents}

What is your son/daughter allergic to?

When were they diagnosed?

What do you think are the main issues for your son/daughter in dealing with their allergy?

What are the main issues for you as a parent?

Do you have any particular concerns about your son/daughter's allergy as they go through their teenage years?

How has your child's allergy impacted on your family?

How is your family's experience different from that of families without allergic children?

What does your son/daughter do to keep his/her allergy under control?

$\infty$ See doctors, nurses, specialists? How often?

$\infty$ Carry Epipen/Anapen?

$\infty$ Avoid certain foods, certain situations?

Do these things work well - why/why not?

How do you see your role in managing your son/daughter's allergy?

Are there specific things you do to help them manage it?

Has this changed as they have got older? If so, how?

Adolescence is often seen as a time when people start to become independent, to take responsibility for themselves, and make the transition to being an adult. 
Do you think your son/daughter's allergy affected this transition?

Can you think of any specific examples of this?

What might help you and your son/daughter manage this transition?

What has your experience of the health services been like?

What has worked well?

What hasn't worked well?

What could have been better?

What - if anything - do you think would help parents to cope better with having allergic children?

Ranking exercise as for adolescents 